\title{
Governança em IFES do Nordeste: concepção, execução e monitoramento da gestão estratégica
}

\author{
Governance in Northeast IFES: \\ design, implementation and \\ monitoring of strategic management
}

\author{
LINNIK ISRAEL LIMA TEIXEIRA* \\ ANTÔNIO JONES BEZERRA DE ALMEIDA** \\ SONIA CASCIANO DE QUEIROZ PAIVA*** \\ MAXWEEL VERAS RODRIGUES****
}

\section{RESUMO}

A governança surge como um novo paradigma distinto da nova gestão pública, cujo conjunto de práticas busca o aperfeiçoamento do desempenho da gestão nas organizações. O TCU tem procurado contribuir com esse aperfeiçoamento e dar consecução à concretização dessas novas demandas. As universidades têm procurado meios de ajudar a garantir o foco da gestão e aduzir ao controle e qualidade do ensino, melhorando a sua gestão por meio do planejamento estratégico e da governança.Objetiva-se relacionar as práticas de estratégia, segundo os princípios da

* Universidade Federal do Ceará. Mestrando em Políticas Públicas e Gestão da Educação Superior pela Universidade Federal do Ceará (UFC), Especialista em Gestão Pública pela Universidade da Integração Internacional da Lusofonia Afro-Brasileira (UNILAB) e Bacharel em Administração pela Universidade Federal do Ceará (UFC). linnik.lima@gmail.com

** Universidade Federal do Ceará. Mestrando em Políticas Públicas e Gestão da Educação Superior pela Universidade Federal do Ceará (UFC), Especialista em Gestão Escolar e Coordenação Pedagógica pela Faculdade Kurios, Licenciado em Ciências Biológicas pela Universidade Estadual do Ceará. almeida.ufc.2010@gmail.com

*** Universidade Federal do Ceará. Mestranda em Políticas Públicas e Gestão da Educação Superior pela Universidade Federal do Ceará (UFC). Graduada em Direito pela Faculdade Católica Rainha do Sertão. soniacasciano@gmail.com

**** Universidade Federal do Ceará. Doutor em Engenharia de Produção pela Universidade Federal de Santa Catarina. Professor Associado 2 do Departamento de Engenharia de Produção (DEPRO) do Centro de Tecnologia da UFC. maxweelveras@gmail.com 
governança pública, com a realidade da gestão em instituições de ensino superior. Por intermédio de uma pesquisa de campo realizada em dezenove instituições federais de ensino superior (IFES) do Nordeste, buscou-se identificar os mecanismos e atores envolvidos na concepção, execução e monitoramento da gestão estratégica das organizações. Os resultados indicaram que as IFES, em sua maioria, democratizam o acesso de diversos atores na formulação do planejamento,mas não promovem um monitoramento das metas estabelecidas; não apresentam qualquer instrumento de plano de ação e apenas e a despeito de possuírem bom desempenho na concepção e execução da gestão estratégica, ainda precisam criar instrumentos eficazes de monitoramento. Palavras-chave:Governança nas organizações. Ensino Superior. Gestão Estratégica.

\section{Abstract}

Governance emerges as a new paradigm distinct from the new public management, whose set of practices seeks to improve the performance of management in organizations. The TCU has sought to contribute to this improvement and achieve the achievement of these new demands. Universities have sought means of to help ensure the focus of management and to adhere to the control and quality of teaching, improving its management through strategic planning and governance. It is intended to relate the strategy practices, according to the principles of public governance, to the reality of management in higher education institutions. Through a field research carried out in nineteen federal institutions of higher education (IFES) in the Northeast, it was sought to identify the mechanisms and actors involved in the conception, execution and monitoring of the strategic management of the organizations. The results indicated that the IFES, in its Majority, democratize the access of diverse actors in the formulation of the planning, but do not promote a monitoring of the established goals; Do not present any instrument of action plan and only and despite having good performance in the conception and execution of strategic management, they still need to create effectual monitoring instruments.

Key-words: Governance in organizations. Higher education. Strategic management. 


\section{INTRODUÇÃo}

Em resposta às novas demandas sociais, as proporções que a expansão do ensino superior tomou no Brasil conduziram a um consequente aumento e descentralização do ambiente administrativo das universidades, cujas ramificações se expandiram, saindo dos grandes centros urbanos e organizando sua estrutura nas cidades do interior. Essas novas dimensões alcançadas pelas universidades levaram a um consequente aumento da exigência de um sistema de planejamento e controles (externo e interno), e um acompanhamento mais acurado das decisões tomadas nos diversos níveis hierárquicos e de relevância estratégica para a instituição.

Assim, os princípios aplicados como boas práticas de governança,em suas diversas formas de manifestação, conduzem ao aumento do desempenho dos processos de controle da gestão, do planejamento à operacionalização dos processos, favorecendo a manutenção da sustentabilidade e perenidade da organização e agregando valor social e capital, contribuindo ainda para o melhoramento da imagem institucional perante a sociedade e perante o mercado.

Ao influenciar diretamente na credibilidade institucional no contexto em que essas organizações se inserem, as boas práticas de governança se alinham, ainda, como importantes orientações estratégicas organizacionais.

Seguindo a tendência das boas práticas de governança corporativa implantadas nas organizações privadas, as organizações públicas têm se alinhado a tais princípios e práticas, aprimorando-as para a aplicação ao setor público. Essa busca pelo aprimoramento dos instrumentos de governança nas IFES tem apresentado retornos significativos nos últimos anos, mas muito há de se fazer.

O presente estudo tem como objetivo, portanto, relacionar as boas práticas de estratégia organizacional, segundo os princípios da governança pública, com a realidade da gestão estratégica em instituições de ensino superior, por meio de uma pesquisa de campo realizada com dezenove instituições federais de ensino superior (IFES) do Nordeste, em que se busca identificar os mecanismos e atores envolvidos na concepção, execução e monitoramento da gestão estratégica dessas instituições. 
Diante do que foi até aqui exposto, o trabalho justifica-se pela dimensão global que as práticas de Governança Pública têm tomado no âmbito do planejamento estratégico e, em particular, na forma como tais práticas vêm sendo exigidas pelos órgãos de controle e executadas nas Instituições Federais de Ensino Superior do Nordeste, trazendo mudanças organizacionais relevantes para essas instituições, cuja proposta central preconiza o interesse público, retornando a eficiência e efetividade dos serviços à sociedade.

A pesquisa mostra-se relevante, portanto, por demonstrar, no quesito gestão estratégica, um pequeno recorte do quadro que se desenha no cenário de mudanças organizacionais ora posto nessas instituições, em alinhamento às recomendações dos órgãos de controle, relativo às IFES do Nordeste.

\section{GOVERNANÇA CORPORATIVA EM CONCEITOS, DEFINIÇÕES E PRINCÍPIOS}

Proclamou-se, hodiernamente, a governança pública como um novo paradigma, para alguns até multiparadigmática distinta da nova gestão pública e da administração pública burocrática ortodoxa (MARTINS; MARINI, 2014, p. 43).Trazendo uma proposta de escopos mais amplos e se colocando numa concepção mais abrangente de governo e sociedade (Op. cit. 2014, p. 43).

De acordo com o setor ao qual se volta, a governança corporativa (GC) assume diferentes definições, no entanto, embasadas nos mesmos princípios norteadores. De acordo com Silva (2006), é um conjunto de práticas que têm por finalidade aperfeiçoar o desempenho de uma companhia, protegendo investidores, empregados e credores, facilitando assim o acesso ao capital. Segundo Rhodes (1996 apud MATIAS-PEREIRA, 2010), pode ser definido, ainda, de forma mais ampla, como um processo complexo de tomada de decisão que antecipa e ultrapassa o governo. Sendo, portanto, consenso entre os difusores do conceito de GC que os princípios basilares da boa governança se alicerçam em transparência, equidade, prestação de contas (accountability) e responsabilidade corporativa, que abrange os princípios cumprimento das leis (Compliance) e ética (STEINERG et al., 2003). 
Silva (2006) lista ainda abordagens dadas para o tema na visãodas principais organizações voltadas ao desenvolvimento das melhores práticas de GC:

IBGC: Governança corporativa é o sistema pelo qual as sociedades são dirigidas e monitoradas, envolvendo os relacionamentos entre acionistas/cotistas, conselho de administração, diretoria, auditoria independente e conselho fiscal. As boas práticas de governança corporativa têm a finalidade de aumentar o valor da sociedade, facilitar seu acesso ao capital e contribuir para sua perenidade. OCDE: A governança corporativa é o sistema segundo o qual as corporações de negócio são dirigidas e controladas, cuja estrutura especifica a distribuição dos direitos e responsabilidades entre os integrantes da corporação, além de definir as regras e procedimentos para a tomada de decisão em relação às questões corporativas. CADBURY:A governança corporativa é o sistema e a estrutura de poder que regem os mecanismos através dos quais as companhias são dirigidas e controladas (SILVA, 2006, p. 16-17).

Segundo asseveram Andrade e Rossetti (2009), desde os anos 80 , e mais fortemente a partir dos anos 90, têm se modificado substancialmente as relações entre o mundo corporativo e a sociedade. Haret, Silveira e Alves (2015) complementam que se, de um lado, a complexidade da sociedade contemporânea passou a exigir postura multidisciplinar e interdisciplinar; de outro, a unidade instituída pela globalização requer o alcance de um resultado comum e integrado. Trata-se, portanto, de exigências inerentes ao comportamento ético com o mercado e seus atores.

Desse modo, o conceito de governança corporativa (GC), que envolve práticas e usos de direitos e deveres dentro das organizações, além de viabilizar a gestão de forma transparente e alinhada com a estratégia empresarial, tem se tornado princípio norteador e pré-requisito para a boa visibilidade das organizações no mercado mundializado. Assim, a discussão sobre o envolvimento e a criação de mecanismos que assegurem tomadas de decisões corporativas com vistas ao interesse dos investidores e demais stakeholders (ANDRADE; ROSSETTI, 2009) têm também, de forma incontestável, 
moderado as exigências de boas práticas de governança corporativa pautadas pelos órgãos públicos, contribuindo para as transformações no setor, a despeito de o foco da governança no setor públicoser imperceptível,por atuar com estruturas e modelos de gestão distintas do setor privado, como propõe Matias-Pereira (2010).

Brasil (2014, p.32) acentua a diferença entre a gestão e a governança corporativa. Segundo a obra citada:

Enquanto a gestão é inerente e integrada aos processos organizacionais, sendo responsável pelo planejamento, execução, controle, ação, enfim, pelo manejo dos recursos e poderes colocados à disposição de órgãos e entidades para a consecução de seus objetivos, a governança provê direcionamento, monitora, supervisiona e avalia a atuação da gestão, com vistas ao atendimento das necessidades e expectativas dos cidadãos e demais partes interessadas.

Depreende-se daí que a relação dos ciclos de monitoramento, avaliação e direcionamento das atividades da gestão, cujos resultados definirão estratégias que pautarão estratégias de planejamento, execução, ação e controle de atividades da gestão, permitirão um feedback às ações de governança que se dará por meio da prestação de contas -accountabilitty.

\section{A LEI de Improbidade Administrativa e a Governança}

A preocupação com o processo de melhoria contínua da qualidade e fiabilidade das informações inseridas nos relatórios gerenciais, anuais, ou de outros tipos de documentos (SILVA, 2006, p. 68) é fator basilar a um dos valores da governança corporativa: o Disclosure - transparência das informações. Essa prática aumenta a transparência da gestão, subsidiando os stakeholders com maior volume de informações úteis e relevantes para o auxílio na tomada de decisões.

O Plano de Desenvolvimento Institucional é a base das estratégias institucionais para que atinjam suas metas e objetivos, conforme o Decreto $\mathrm{n}^{\mathrm{o}}$. 5.773/2006. Sabendo que a administração pública está submetida à legalidade estrita, e no intuito de oferecer coesão à leitura, nesta seção serão abordados breves conceitos de 
governança, tanto no setor privado, como no público, que embasarão os argumentos que serão apresentados, fazendo conexão entre governança e probidade.

Deve-se ainda prever que os agentes de governança tenham a responsabilidade de assegurar que toda a organização esteja em conformidade com os seus princípios e valores, refletidos em políticas, procedimentos e normas internas, e com as leis e os dispositivos regulatórios a que a organização esteja submetida. A efetividade desse processo constitui o sistema de conformidade (compliance) da organização (IBGC 2015).

Slomski et al. (2008, p. 8 apud BIZERRA; ALVES; RIBEIRO, 2012) definem governança corporativa como "o sistema pelo qual as sociedades são dirigidas e monitoradas, em que, por meio de mecanismos específicos, gestores e proprietários procuram assegurar o bom desempenho da organização para aumento de sua riqueza".

Em 2013, o então presidente do Tribunal de Contas da União, João Augusto Ribeiro Nardes, definiu governança no setor público:

...como um conjunto de mecanismos de liderança, estratégia e controle postos em prática para AVALIAR, DIRECIONAR E MONITORAR a atuação da gestão, com vistas à condução de políticas públicas e à prestação de serviços de interesse da sociedade.

Percebe-se que nessa definição são aliadas a liderança, a estratégia e o controle dentro do serviço público. Na definição de Slomski, encontra-se como finalidade para governança, no setor privado, o aumento da riqueza patrimonial de uma empresa, um crescimento pessoal.

Considerando que os serviços do setor público não possuem tal finalidade, pode-se afirmar que a governança conta com a prestação de serviços do agente público, que pode liderar, traçar estratégias, mas, por sua vez, sofrerá o controle do Estado, em função do interesse público, no sentido de evitar danos ao erário, visto que este pertence à coletividade, não podendo ser usufruído de maneira egoística pelos atores públicos.

Existem valores que são constatados em relação à governança corporativa. Quatro são apresentados por Andrade e Rossetti (2009 
apud BIZERRA; ALVES; RIBEIRO,2012): “Fairness - senso de justiça, com equidade no tratamento dos acionistas; Disclosure - transparência das informações; Accountability - prestação responsável de contas; e Compliance - Conformidade no cumprimento de normas reguladoras".

Transportando tais valores para o setor público, ressalta-se inicialmente a equidade que, de acordo com Bigotte Chorao (1990 apud AMARAL NETO, 2004):

O ponto de partida é o conceito de Epieikeia, um princípio de interpretação da lei positiva que permite justificadamente um comportamento que se afasta da letra, mas é conforme com a mente do legislador. Ou, ainda, uma correção da lei quando, por causa de sua universalidade, mostra-se incapaz de atender a determinada situação concreta. Consiste, assim, em uma atuação do intérprete que procura aplicar a norma jurídica de modo aperfeiçoado, o que pressupõe a existência de uma lei diversa da lei positiva, aplicando-se os preceitos daquela sempre que insuficientes os desta.

A equidade, conforme esse conceito, permite que se decida além da letra da lei, desde que permaneça no que se propunha o legislador ao emitir a norma. $\mathrm{O}$ administrador público está limitado ao que estabelece a lei, seguindo o princípio da legalidade, devendo até sua discricionariedade estar estabelecida previamente. Dessa forma, encontra-se liberdade do gestor público em liderar, considerando o que a legislação vigente, atuando de acordo com a conveniência e a oportunidade que deve ser aplicada para o bem público, buscando o justo dentro dos parâmetros legais.

Nesse compasso, passa-se a abordar a transparência das informações, que na atualidade conta com o reforço da Lei $n^{0}$. 12.527/2011. Essa norma deve ser observada pela União, Estados, Distrito Federal e Municípios, e tem a finalidade de "assegurar o direito fundamental de acesso à informação". Essa norma proporciona a oportunidade de uma gestão transparente pelo setor público, quando se dá o amplo acesso à informação, a documentos, a atividades que cada órgão exerce etc., sujeitando a medida disciplinar àquele que desrespeitar o seu comando. 
Abordando ainda os valores da governança, tem-se a prestação responsável de contas. Nesse quesito, a Constituição da República Federativa do Brasil de 1988 estabelece, em seu artigo 70, e seguintes:

Artigo 70. A fiscalização contábil, financeira, orçamentária, operacional e patrimonial da União e das entidades da administração direta e indireta, quanto à legalidade, legitimidade, economicidade, aplicação das subvenções e renúncia de receitas, será exercida pelo Congresso Nacional, mediante controle externo, e pelo sistema de controle interno de cada Poder. Parágrafo único. Prestará contas qualquer pessoa física ou jurídica, pública ou privada, que utilize, arrecade, guarde, gerencie ou administre dinheiros, bens e valores públicos ou pelos quais a União responda, ou que, em nome desta, assuma obrigações de natureza pecuniária. Art. 71. O controle externo, a cargo do Congresso Nacional, será exercido com o auxílio do Tribunal de Contas da União, ao qual compete: [...]II - julgar as contas dos administradores e demais responsáveis por dinheiros, bens e valores públicos da administração direta e indireta, incluídas as fundações e sociedades instituídas e mantidas pelo Poder Público federal, e as contas daqueles que derem causa a perda, extravio ou outra irregularidade de que resulte prejuízo ao erário público;[...] VI - fiscalizar a aplicação de quaisquer recursos repassados pela União mediante convênio, acordo, ajuste ou outros instrumentos congêneres, a Estado, ao Distrito Federal ou a Município; [...]VIII - aplicar aos responsáveis, em caso de ilegalidade de despesa ou irregularidade de contas, as sanções previstas em lei, que estabelecerá, entre outras cominações, multa proporcional ao dano causado ao erário...

Percebe-se, numa breve análise do texto constitucional, que o Poder Constituinte pensava nos gestores da nação como sujeitos livres para gerir, mas respeitando um padrão legal, legítimo e econômico, não admitindo ilegalidades, prezando pelo bom uso dos bens e valores públicos, sendo tudo isso constatado na prestação de contas, que no contexto nacional é obrigatória, conforme parágrafo único do artigo 70, da CRFB/88.

Concluindo esta abordagem, temos a "conformidade no cumprimento de normas reguladoras". Aqui se repete o princípio da 
legalidade estrita, que impele o administrador público agir (liderar/ traçar estratégias) dentro do que determina a lei. Consoante o artigo 37 da CRFB/88: "A administração pública direta e indireta de qualquer dos Poderes da União, dos Estados, do Distrito Federal e dos Municípios obedecerá aos princípios de legalidade, impessoalidade, moralidade, publicidade e eficiência".

Diante dessas considerações, voltando-se para a relação governança versus improbidade, reconhecendo o caráter cogente da Lei no. 8.429/1992, conhecida como a Lei da Improbidade Administrativa, constata-se uma natureza peculiar dessa norma, pois serve de auxílio aos propósitos da governança, tomando por base o conceito de governança no setor público, já exposto.

O conceito evidencia a necessidade de uma gestão responsável que deve ser avaliada, direcionada e monitorada, sempre em razão do bem comum. O que é a lei de improbidade administrativa, senão uma forma de alertar ao agente público as sanções que lhes serão aplicadas caso se esgueire em atuar: 1) enriquecendo ilicitamente; 2) causando prejuízo ao erário público; 3) atentando contra os princípios da administração pública?

O Tribunal de Contas da União estabelece dez passos para uma boa governança:

1) escolha líderes competentes e avalie seus desempenhos; 2) lidere com ética e combata os desvios; 3) estabeleça sistemas de governança com poderes de decisão balanceados e funções críticas segregadas; 4) estabeleça modelo de gestão da estratégia que assegure seu monitoramento e avaliação; 5) estabeleça a estratégia considerando as necessidades das partes interessadas; 6) estabeleça metas e delegue poder e recursos para alcançá-las; 7) estabeleça mecanismos de coordenação de ações com outras organizações; 8) gerencie riscos e institua os mecanismos de controle interno necessários; 9) estabeleça função de auditoria interna independente que adicione valor à organização; e 10) estabeleça diretrizes de transparência e sistema de prestação de contas e responsabilização (BRASIL, 2014).

A liderança com ética; a estratégia monitorada e avaliada; a consideração das necessidades do público-alvo da organização; a 
auditoria interna independente; a transparência, prestação de contas e responsabilização são passos que se coadunam com os valores da governança corporativa, bem como aperfeiçoam a atuação do gestor público em favor da coletividade, que é o que pretende salvaguardar a Lei $n^{\circ}$. 8.429/1992.

Conforme Rosseti (2015):

A criação de valor provém de sistema de governança competente para alinhar a estratégia das companhias a ambiente de negócios sem precedentes em dimensões, oportunidades e desafio, mas não se pereniza sem atenção equivalente a valores morais e a demandas legítimas de todas as partes atingidas por suas deliberações e iniciativas.

A Lei no ${ }^{8} 8.429 / 1992$ preza por vários princípios atinentes à gestão do bem público, e todo agente público deve estar atento a tais princípios. A saber, o artigo $4^{\circ}$. dispõe: “Os agentes públicos de qualquer nível ou hierarquia são obrigados a velar pela estrita observância dos princípios de legalidade, impessoalidade, moralidade e publicidade no trato dos assuntos que lhe são afetos".

Rosseti (2015) se manifesta, informando que o valor é criado, advindo de um sistema de governança que consiga alinhar a estratégia ao negócio, entretanto, os valores morais não devem ser debelados, pois assim o ganho de valor não se perpetuará.

De forma semelhante, segue o entendimento da administração pública, que deve gerir competentemente, estabelecendo metas, encarando riscos, considerando o ambiente externo, buscando o bem comum de forma a não recair em atos ímprobos. Logo, implantar orientações emanadas de órgãos superiores exige, além de respeito às normas vigentes, cuidado ao estabelecer as estratégias, visto que estas não vêm traçadas em normas gerais, devendo o gestor público, com acuidade e parcimônia, não ultrapassar as margens legais e ainda obter sucesso no seu desempenho.

A seção seguinte trará uma abordagem do processo de acolhimento dos conceitos e práticas da governança corporativa, surgidos em organizações privadas, para o uso em empresas estatais. 


\section{A Governança Corporativa e o Estado}

De acordo com Carvalho e Vieira (2003), a homogeneidade de estruturas e ações das organizações utiliza com frequência os princípios institucionais que compreendem a similitude, ou seja, isomorfismos, como uma busca de legitimidade. Em uma abordagem mais restrita, nesse contexto (IBID.,2003, p. 32), acentua que:

As mudanças isomórficas, por meio de mecanismos miméticos, costumam se produzir quando uma organização, em razão de seus temores tecnológicos, antagonismos em seus objetivos ou exigências institucionais, adota os procedimentos e práticas já desenvolvidos e provados em outras organizações que pertencem a seu ambiente específico.

Aparentemente, a finalidade perseguida pelas organizações que demonstram um comportamento isomórfico em relação a outras parece a autodefesa frente a problemas para os quais ainda não têm soluções próprias (CARVALHO; VIEIRA, 2003, p. 32).Nesse embasamento,defende-se que a governança pública fundamenta-se nos princípios da governança privada, introduzindo, na gestão pública, os preceitos de gestão de entidades privadas, buscando maior eficiência na gestão, promovendo maior eficiência no retorno dos serviços ao cidadão e aos demais stakeholders, quando Matias-Pereira (2010, p. 113) assinala que "considerando as novas tendências de reestruturação da gestão pública voltada para o cidadão que se caracteriza, hodiernamente, pelo reconhecimento dos limites de sua atuação, que passou a ser mediada pela ação do setor privado e das organizações do terceiro setor". Têm-se, portanto,desafios a se transporem, na busca pela adequação da cultura de boas práticas de governança à realidade do setor público, que há muito padece de descrédito em seus modelos de gestão, cujos meandros se mostram permeados por uma burocracia que se pauta em uma cultura eticamente pouco ortodoxa.

Vilela e Veloso (2014 apud NETO, 2014) corroboram o exposto ao afirmar que, "quanto mais os abusos são constatados, nas esferas públicas e privadas, maior a desconfiança e maior a procura por modelos de gestão, que venham solucionar problemas pela implementação de sistemas mais confiáveis". 
Nesse contexto, as dimensões da governança, publicadas no Study 13 da International Federation of Accountants (IFAC), em 2001, são padrões de comportamento, estrutura e processos organizacionais, controle e relatórios externos que norteiam o comportamento da gestão pública(SALES et al., 2015), por meio da adequação dos princípios da boa governança,trazidos para o Estado.

O Conselho da Federação Internacional de Contadores (IFAC), por meio do Comitê do Sector Público (PSC), elabora, de forma coordenada, relatórios das necessidades dos gestores envolvidos em auditorias financeiras e de contabilidade no setor público em todo o mundo. Desataquese, o termo "setor público" como designação dos governos nacionais, regionais (por exemplo, estadual, territorial), locais (por exemplo, cidade) e os relacionados a entidades governamentais (por exemplo, agências, conselhos, comissões e empresas) (IFAC, 2001, preface-i).

Segundo OECD (2004apudFONTES FILHO e PICOLIN, 2008), as especificidades da empresa estatal apontam para um conjunto de restrições, quanto à plena adesão às mesmas práticas de governança indicadas ao setor privado, como:

...restrições mais brandas em termos orçamentários, que podem protegê-las contra ações de tomada de controle via mercado e falência; muitas estatais, por sua própria natureza, operam em áreas nas quais a competição com o setor privado é pequena ou inexistente; diferenças nos padrões de transparência e prestação de contas em relação ao setor privado; falta de clareza na existência de um proprietário, existindo, no entanto, potenciais proprietários buscando objetivos diferentes e construindo uma cadeia difusa de accountability (FONTES FILHO; PICOLIN, 2008).

Reforçando, portanto, a publicação "Princípios de Governança Corporativa da OCDE" de 2004, e atualizada em 2015, as diretrizes da OCDE são recomendadas aos governos como forma de garantir que as empresas estatais operem de forma eficiente, transparente e responsável (SILVA; SANTOS, 2016). Com a finalidade de concretização dessas novas demandas, o Tribunal de Contas da União 
(TCU) assevera que tem buscado contribuir com o aperfeiçoamento da administração pública em benefício da sociedade, por meio de acordo de cooperação com a OCDE, para a execução de um projeto no período de 2013 a 2016 (BRASIL, 2016b).

A discussão até aqui posta sobre a adoção da governança, cujas práticas têm sido aceitas, institucionalizadas e aplicadas pelos entes do Estado, ratifica a proposta de mudança isomórfica, levantada no início da seção, onde, "por meio de mecanismos miméticos", "em razão de seus temores tecnológicos, antagonismos em seus objetivos ou exigências institucionais", produziu-se a adoção de "procedimentos e práticas" de Governança Corporativa, “já desenvolvidas e provadas" em organizações privadas.

\section{TCU, IFES E INSTITUCIONALIZAÇÃO DAS PRÁTICAS DE GOVERNANÇA}

As universidades se encontram inseridas na estrutura dos órgãos públicos, e por isso possuem autonomia administrativa, conforme o artigo 207 da Constituição Federal de 1988 (SALES et al., 2015, p. 2). Essas instituições "gozam de autonomia didático-científica, administrativa e de gestão financeira e patrimonial, e obedecerão ao princípio de indissociabilidade entre ensino, pesquisa e extensão" (BRASIL, 1988), a despeito disso, os recursos tornam-se escassos a cada ano, diante das exigências sociais pautadas pelas novas demandas do mercado, limitando a efetivação das atividades da tríade que deve ser o objetivo precípuo das universidades e para a qual se deve nortear todo o seu planejamento estratégico.

Desse modo, como delineado em seções anteriores, o TCU tem exercido um papel preponderante na aplicação das boas práticas de Governança Corporativa, no papel de Entidade Fiscalizadora Superior (EFS), constatação corroborada, por meio da execução do projeto aplicado com a cooperação da OCDE(BRASIL, 2016b).

A governança pública, para ser efetiva, pressupõe a existência de um Estado de Direito; de uma sociedade civil participativa no que tange aos assuntos públicos; de uma burocracia imbuída de ética profissional; de políticas planejadas de forma previsível, aberta e transparente; e de um braço executivo que se responsabilize por suas ações World Bank (2007 apud BRASIL, 2014, p. 33). 
No entendimento do Banco Mundial, a legitimidade, a equidade, a responsabilidade, a eficiência, a probidade, a transparência e a accountability são princípios da boa governança (BRASIL, 2014, p. 33) e,tendo muito mais que demonstrar as responsabilidades elencadas nessas boas práticas, não prescindindo desses princípios, estão as Instituições Federais de Ensino Superior (IFES).Vilela e Veloso (2014, p. 7) ratificam, afirmando que "não parece exagero afirmar que os benefícios trazidos às IFES que adotaram o sistema de governança validaram sua utilização em qualquer tipo de organização, já que o foco de tal sistema são os ganhos com a qualidade" . Ressalte-se aqui que "as instituições de ensino superior brasileiras vivem num ambiente de mudanças e transformações que desafiam suas tradicionais estruturas e suas velhas e conhecidas estratégias" (NOGUEIRA; GARCIA; RAMOS, 2012) e,nesse contexto, o planejamento estratégico aliado às boas práticas de governança ajudam a garantir o foco da gestão e a aduzir o processo de políticas de controle(BRASIL, 2016b), elevando a qualidade do ensino e melhorando suas práticas de gestão, garantindo longevidade e sustentabilidade frente à sociedade(VILELA; VELOSO, 2014).

Visando à ratificação do problema e em alinhamento aos objetivos aportados, a seção seguinte descreverá os procedimentos tomados para a execução da pesquisa, onde será caracterizada metodologicamente e serão apresentados os métodos de pesquisa, instrumentos e técnicas que viabilizaram sua efetivação.

\section{PROCEDIMENTOS METODOLÓGICOS}

Segundo a classificação de Prodanov e Freitas (2013), a pesquisa classifica-se como um estudo de campo, quanto aos seus meios, e como um estudo exploratório, quanto aos seus fins. Os autores explicam que o estudo de campo tem como objetivo a busca de respostas acerca de problemas ou hipóteses que queremos provar. Além disso, Gil (2008) afirma que esse tipo de pesquisa não se concentra em descobrir como um fenômeno se distribui em determinada população, mas sim ao aprofundamento de questões propostas. No caso do estudo aqui apresentado, é pesquisada uma parcela representativa das Instituições Federais de Ensino Superior do Nordeste a respeito 
dos seus processos de formulação, execução e monitoramento do seu planejamento estratégico.

A pesquisa exploratória, segundo Gil (2008), é aquela desenvolvida com o objetivo de fornecer uma visão geral, do tipo aproximativo, de determinado fato, sobre um tema que foi pouco explorado. De acordo com pesquisa bibliográfica realizada, revelou-se que o assunto é pouco abordado em IFES do Nordeste, justificando o caráter exploratório da pesquisa.

Os dados do estudo são provenientes de questionário aberto, que resulta em uma pesquisa qualitativa. Segundo Flick (2009), a pesquisa qualitativa trabalha, acima de tudo, com textos, de onde partem os métodos de interpretação.

\subsection{Método de Coleta de Dados}

Para subsidiar a pesquisa, foi utilizada ferramenta desenvolvida pela Controladoria Geral da União. Trata-se do Sistema Eletrônico de Informação ao Cidadão (e-SIC), que serve "para controle e registro dos pedidos de acesso dos órgãos e entidades do Poder Executivo Federal, viabilizando o acesso à informação" (BRASIL, 2016a).

A criação de um sistema eletrônico para dar acesso à informação dos órgãos vinculados ao Poder Executivo Federal, tanto às pessoas naturais, como às jurídicas, está prevista no Decreto $n^{\circ}$. 7.724, de 16 de maio de 2012onde, em seu artigo $11 \S 1^{\circ}$, informa que o pedido de informação, deve ser "apresentado em formulário padrão, disponibilizado em meio eletrônico e físico, no sítio na Internet e no SIC dos órgãos e entidades".

Como as Instituições pesquisadas são submetidos ao Poder Executivo Federal, os questionamentos formulados que foram enviados, via formulário eletrônico, pelo e-SIC. Para o acesso ao formulário, é necessário ser usuário e ter senha de acesso, conseguidos mediante cadastro. Nele contém as opções de registrar pedidos e consultá-los. No início da demanda, é necessário informar a instituição alvo da consulta. Em seguida, escolhe-se a forma de recebimento da resposta, que pode ser: a) com avisos por e-mail - nesse caso deve-se entrar no sistema para consultar a resposta; b) pessoalmente; ou c) por correspondência física.

Há um espaço específico para o detalhamento da solicitação, sendo possível enviar documentos anexos. As respostas das instituições podem vir, tanto no espaço de detalhamento, como em forma de anexos. 
Neste estudo, foram consultadas 28 instituições Federais de Ensino: 10 Institutos Federais e 18 Universidades Federais da Região Nordeste do Brasil. Esses órgãos tiveram o prazo inicial para resposta de até vinte dias, conforme o artigo 15, $\S 1^{\circ}$. do Decreto no. 7.724/2012, entre os meses de julho a outubro do ano de 2016.

Optou-se pelo recebimento das respostas com avisos por e-mail, tendo que se entrar no sistema para o seu acesso. Dentro do prazo, foram retornadas as respostas de 19 instituições: 11 Universidades e oito Institutos Federais. Uma universidade pediu prorrogação de prazo, contando com mais dez dias para emitir as informações solicitadas, que já foram fornecidas. Sendo que oito dessas continuaram com status em tramitação. Dessas, seis não consultaram a solicitação de informações; um pedido consta como respondido, mas a instituição não forneceu qualquer informação, de fato; e uma está com o status de pedido em atendimento.

Foram escolhidas as questões do Mecanismo "Estratégia", diante do que propõe o Referencial Básico de Governança do Tribunal de Contas da União. Dentro desse mecanismo, associou-se um conjunto de componentes (E1, E2 e E3), que contribuem, direta ou indiretamente, para o alcance dos objetivos (BRASIL, 2014), como mostra a Figura 1:

Figura 1: Componentes dos mecanismos de governança

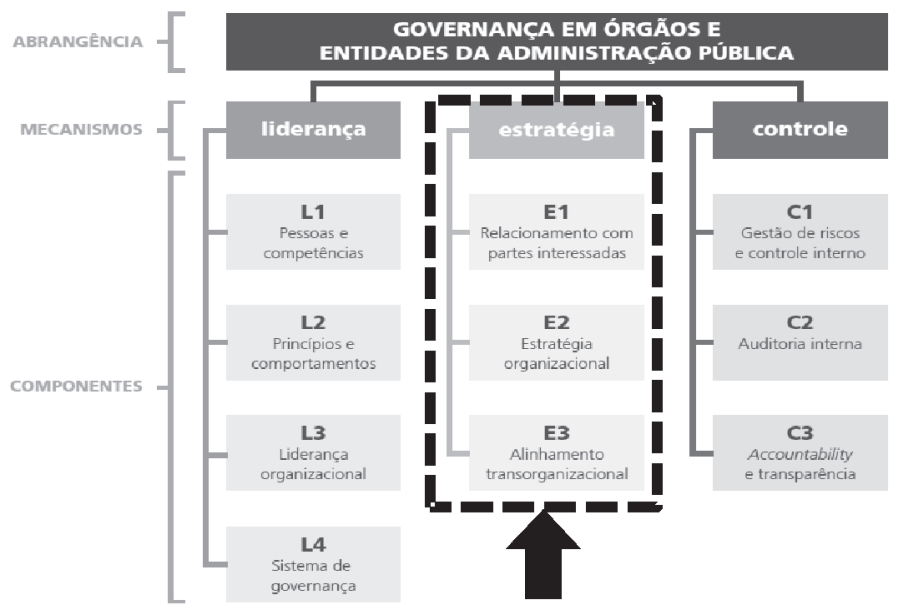

Fonte: (BRASIL, 2014) - destaque dado pelos autores. 
A seção seguinte aportará a discussão sobre as respostas retornadas pelas instituições inquiridas pelas questões pautadas nos componentes (E1, E2 e E3) do mecanismo "Estratégia", como mostra a Figura 1: E1 - Relacionamento com partes interessadas; E2 - Estratégia organizacional; E3 - Alinhamento trans-organizacional.

As perguntas enviadas às Instituições seguiram os critérios que foram resumidos no Quadro 1:

Quadro 1: Critérios para a elaboração das Perguntas

Prática E2.1 - Estabelecer modelo de gestão da estratégia que considere aspectos como transparência e envolvimento das partes interessadas.

EXPLICAÇÃO:Implica definir modelo de gestão da estratégia, considerando aspectos como transparência e envolvimento das partes interessadas. Tal modelo deve explicitar os processos necessários, incluindo as etapas de formulação, desdobramento e monitoramento da estratégia. Além disso, explicita como as instâncias internas de governança participam da avaliação, direcionamento e monitoramento da estratégia e como as partes interessadas são envolvidas nessas atividades.

PERGUNTA(S): 1) Além da legislação federal, a IFES conta com algum modelo de construção e desenvolvimento do PDI, que defina as etapas, monitoramento das estratégias e os participantes?

Prática E2.2 - Estabelecer a estratégia da organização.

EXPLICAÇÃO: Consiste em definir a missão, a visão e a estratégia da organização, compreendendo objetivos, iniciativas, indicadores e metas de desempenho. Pressupõe também o envolvimento das partes interessadas na formulação da estratégia e a sua execução.

PERGUNTA(S): 2) Que atores estão envolvidos na formulação do PDI e quais são os níveis de sua participação na formulação de estratégias e indicadores?

3) Quem são os atores envolvidos na execução das estratégias estabelecidas no PDI?

Prática E2.3 - Monitorar e avaliar a execução da estratégia, os principais indicadores e o desempenho da organização.

EXPLICAÇÃO: Pressupõe que estejam definidas tanto a estratégia da organização como as diretrizes para o monitoramento e avaliação da execução dessa estratégia. Implica, ainda, acompanhar a execução das iniciativas estratégicas e avaliar o desempenho da organização, adotando ações de melhoria sempre que necessário. Como resultado, esperase que a estratégia da organização seja executada de acordo com os objetivos e as metas definidos.

PERGUNTA(S): 4) Há monitoramento do cumprimento dos objetivos estratégicos? Em caso afirmativo, como ocorre o monitoramento?

5) Existe plano de ações de melhorias para objetivos que não foram alcançados?

Fonte: Elaboração dos autores com base em Brasil (2014). 


\section{RESULTADOS E DISCUSSÕES}

Nesta seção, serão apresentadas e discutidas as respostas fornecidas pelas IFES sobre as questões enviadas pelo e-SIC e relacionadas ao desenvolvimento do planejamento estratégico que, no caso das instituições federais de ensino superior (IFES), esse planejamento é registrado em um documento chamado de Plano de Desenvolvimento Institucional (PDI).

Os nomes das Instituições serão preservados, sendo somente denominadas "IFES", seguidos de um numeral arábico que as diferenciará ao longo da discussão.

\section{Pergunta 1: Além da legislação federal, a IFES conta com al-} gum modelo de construção e desenvolvimento do PDI, que defina as etapas, monitoramento das estratégias e os participantes?

Na perspectiva do modelo de construção do PDI, oito IFES afirmaram não possuir um modelo próprio, seguindo apenas a legislação federal. A IFES 10 justificou a ausência pelo fato de o processo de elaboração do Plano de Desenvolvimento Institucional depender da conjuntura específica da época do desenvolvimento que leva a desenvolver métodos específicos que variam no nível de mobilização da comunidade. A IFES 07 explica que um modelo está em fase de estudo, pois "foi detectada a necessidade de mudança que contemple, de forma sistêmica, perspectivas, objetivos estratégicos, iniciativas e indicadores para monitoramento". De igual modo, a IFES explica que não há um modelo específico, mas há a definição de comissões para a definição das estratégias.

Oito IFES afirmaram que, além da legislação federal, contam com manuais e outros documentos institucionais para balizar o processo de construção do PDI. No entanto, apenas três instituições transformaram os métodos em manuais institucionais. Nessas instituições, há um elemento central que é o estabelecimento de comissões ou grupos de trabalhos responsáveis por alguma temática ou eixo específico. A IFES 12 respondeu sobre a existência de um Plano Estratégico Institucional, que é desdobrado ao se elaborar o PDI. Ademais, explicou que a elaboração do documento segue os princípios do Balanced Scorecard (BSC), com o desenvolvimento de 
mapa estratégico. A IFES 16, que também tem um método específico de elaboração do PDI, utiliza o Design Thinking nas reuniões com a comunidade e gestores para a geração de propostas e ideias. Duas IFES afirmaram ter metodologia de elaboração de PDI, mas não explicaram como é a sua ocorrência.

O avanço da governança nas instituições públicas depende de um planejamento estratégico bem realizado. As respostas das IFES indicam que mais de $50 \%$ dessas não possuem metodologia própria ou apresentam uma metodologia imprecisa, o que é preocupante, pois um elemento básico da governança é a institucionalização de práticas e procedimentos constantes, que repassam a ideia de transparência e controle e possibilitam transmissão de confiança para o público.

\section{Pergunta 2: Que atores estão envolvidos na formulação do PDI e quais são os níveis de sua participação na formulação de estratégias e indicadores?}

Doze IFES indicaram claramente a participação das categorias discentes, docentes e de técnico-administrativos. Em relação ao modelo de comissões, é verificada a existência de duas vertentes: a primeira centraliza uma comissão de elaboração das propostas, que visita os campi para a coleta de ideias e propostas, como é o caso da IFES 03, que explica: "uma comissão foi formada e visitou os campi, apresentando o projeto e colhendo proposições para definições dos objetivos institucionais"; a segunda vertente, mais numerosa, é descentralizada, em que comissões são desenvolvidas em cada campus, com a participação de diversos segmentos acadêmicos. A IFES 4 destaca que "os docentes, técnicos administrativos (sic) e discentes [...] constituíram uma comissão e tiveram a responsabilidade de reunir o restante da comunidade interna para definir a estratégia (objetivos, indicadores e metas) do seu campus de lotação". Além disso, as IFES 6, 9 e 18 enfatizaram outro importante segmento a ser consultado na elaboração do PDI: a comunidade externa. A IFES 12, por exemplo, indica que a comunidade externa participa por meio de consulta pública, através de questionários, e entrevistas feitas com lideranças locais. Também é importante destacar que cinco IFES apontaram o 
uso de sites ou blog como canais de integração com o público, para fornecimento de informações e recebimento de sugestões.

Três IFES informaram que os atores envolvidos na elaboração do PDI são membros da alta gestão da instituição e diretores envolvidos com as atividades de cada temática. Outras IFES indicaram que a elaboração envolve a comunidade acadêmica, porém não apontaram atores específicos nem os seus níveis de participação.

Novamente algumas instituições destacam o papel de ferramentas organizacionais na elaboração de seu PDI. A IFES explica que a análise SWOT é realizada na fase inicial, momento em que são identificadas as forças, as fraquezas, as oportunidades e ameaças, que serviu de base para a construção dos objetivos. A IFES 11 aponta a avaliação institucional como importante fonte de informações de diagnóstico institucional.

As respostas das IFES indicam que a maior parte delas busca a participação dos membros da comunidade universitária, porém variam quanto ao nível de participação de cada segmento. Comissões centralizadas podem apresentar a vantagem de conhecer cada campus e perceber similaridades possíveis de serem alinhadas em objetivos que atinjam públicos de diferentes campi. Outra vantagem é que essas comissões, por terem visão do todo, impedem que existam estratégias conflitantes. No entanto, comissões descentralizadas são mais eficazes ao aproximar a comunidade acadêmica local e identificar atores-chave no processo de participação. A análise da eficiência sobre a centralização ou de descentralização dependerá do tamanho e da estrutura da IFES, mas foge ao escopo do presente estudo.

\section{Pergunta 3: Quem são os atores envolvidos na execução das estratégias estabelecidas no PDI?}

O terceiro questionamento suscitou uma variedade de respostas: Quatro IFES não responderam à pergunta; três IFES identificaram a administração superior como as responsáveis pela execução das estratégias; duas IFES identificaram os docentes, técnicos e discentes como agentes de execução das estratégias. É interessante refletir sobre o papel que essas três categorias têm na execução das estratégias. De fato, as IFES estabelecem metas na área de ensino, 
pesquisa e extensão, áreas em que docentes e discentes têm papel decisivo no alcance das metas.

Três IFES apontaram que os atores envolvidos na execução das estratégias são aqueles que trabalham diretamente na área. Muito interessante é a resposta da IFES 04, ao afirmar que a execução é feita por todos os servidores que possuem vínculo direto com as metas da sua área de atuação, porém a responsabilização pelo resultado da meta cabe à respectiva direção e pró-reitoria. A resposta representa um avanço na governança à medida que aponta o elemento responsabilização, termo utilizado na temática de governança e princípio básico da accountability.

Por último, duas IFES interpretaram erroneamente a pergunta, indicando os atores responsáveis pela participação nas comissões.

\section{Pergunta 4: Há monitoramento do cumprimento dos objetivos estratégicos? Em caso afirmativo, como ocorre o monitoramento?}

O monitoramento dos objetivos estratégicos é realizado por 13 IFES pesquisadas, no entanto, a forma de monitoramento é diversa e algumas indicam um entendimento limitado quanto ao conceito de monitoramento.

Quatro IFES associaram o conceito de monitoramento à prestação de contas anual, por meio do Relatório de Gestão ou outros instrumentos de prestação de contas. A IFES 04, por exemplo, destaca que os objetivos estratégicos são medidos ao fim do ano e apresentados sob forma de relatório de gestão. A IFES 10 confunde avaliação com monitoramento, explicando que o monitoramento das metas ainda está associado à avaliação institucional, de modo que é realizada anualmente, além de informar que algumas metas só podem ser avaliadas no final; além disso, a referida instituição reconhece que alguns objetivos institucionais não dialogam com as metas traçadas no PDI. Três IFES confirmam a existência de monitoramento, realizada por unidades responsáveis pelo planejamento, mas não explicam como ocorre tal monitoramento.

A IFES 04 apresentou um período trimestral de atividades de monitoramento, o mais curto entre as IFES, momento em que também prestam contas; a IFES 12 também aplica o monitoramen- 
to como algo constante, utilizando períodos constantes e séries temporais.

Quatro IFES informaram que estão fazendo uso de softwares de monitoramento de indicadores, sendo que três delas usam o GEPLANES, um software livre de acompanhamento de planejamento estratégico,onde é possível gerenciar as medidas, as metas e os seus desdobramentos, os indicadores e as anomalias. A utilização de plataformas informatizadas é um grande salto no aprimoramento e monitoramento das metas estratégicas, visto que conferem mais rapidez na disponibilização e discussão das metas, além de facilitar a comparação entre diferentes unidades acadêmicas e também entre as mesmas unidades em diferentes períodos, alicerçando a visão dos gestores para a tomada de decisões.

Três IFES informaram que não possuem monitoramento, mas estão em fase de implantação de uma ferramenta para o acompanhamento; quatro IFES responderam que não executam monitoramento; uma IFES indicou que não existe um monitoramento institucionalizado, mas que cada setor faz o seu próprio monitoramento.

Portanto, observa-se que o monitoramento correto dos indicadores ainda é uma realidade pouco observada nas IFES, em parte provocada pela confusão no conceito de monitoramento, avaliação e prestação de contas, ou ainda, provocada por limitações de pessoal ou tecnológica.

Pergunta 5: Existe plano de ações de melhorias para objetivos que não foram alcançados?

A parte de plano de ações para melhorias apresentou o resultado menos satisfatório: 14 IFES não têm um plano definido para trabalhar objetivos que não foram alcançados. Dessas, cinco IFES afirmam que os objetivos não alcançados são redefinidos ou reprogramados, sem indicar a existência de algum estudo ou mecanismo para a identificaçãoe mitigação das falhas. A IFES 18 explicou que "não há aparato técnico e metodológico" que permita a realização de um plano de ação.

A IFES 04, que apresentou, ao longo das perguntas, uma gestão planejada, reconheceu "que possui fragilidade quanto a um plano 
de ação para corrigir os objetivos não alcançados". De forma semelhante, a IFES 10 se justifica,ao afirmar "que não chegou a este nível de precisão e que necessita avançar nos mecanismos de governança e gestão estratégicos". A IFES 13 declara que "para algumas pró-reitorias foram construídos planos de ação, visando o alcance de metas previstas para cada exercício. Destaca-se que essas ações ainda são um tanto insipientes, mas já existe uma tendência de que cada unidade construa seu plano de ação para garantia da execução das suas metas", portanto, não foi institucionalizado.

Conforme já destacado, plataformas informatizadas são instrumentos importantes para a operacionalização do planejamento estratégico. Das quatro IFES que realizam plano de ação, duas contam com o software GEPLANES para o tratamento das "anomalias", nome utilizado para identificar problemas que impediram o alcance das metas. Curiosamente, a IFES 01, que informou na pergunta anterior possuir o GEPLANES, respondeu que não possui plano de ação de melhoria, fato que pode indicar que o software não está sendo usado em todas as suas potencialidades, ou que há desconhecimento ou despreparo técnico quanto ao uso das suas ferramentas.

\section{CONSIDERAÇõES FINAIS}

Diversos autoresvêm discutindo a gestão estratégica de Instituições de Ensino Superior, sem que sejam apresentados aspectos conclusivos no que se refere ao modelo maisapropriado ou eficaz de gestão dessas organizações (MAINARDES; MIRANDA; CORREIA, 2011).No entanto, para as IFES, há muito esse modelo vem se desenhando, estimulado pelas exigências pautadas pelos órgãos de controle e pelos sistemas de avaliação do MEC. Andriola (2009) justifica que o planejamento é o instrumento de implantação das políticas estabelecidas, enquanto a avaliação é a atividade de verificação e julgamento de planos, programas e projetos.

A consciência cidadã nos tempos atuais requer instituições públicas com ações transparentes e decisões cada vez mais democráticas, em que a comunidade onde estão inseridas participe e conheça as decisões estratégicas. É nesse contexto que a governança corporativa, antes restrita ao setor privado, vem ganhando espaço dentro da esfera pública. É primordial que as organizações públicas 
tenham práticas de gestão estratégicas solidamente institucionalizadas e democraticamente concebidas. No contexto das Instituições Federais de Ensino Superior (IFES), ambientes universalizados, por sua própria natureza, essas características lhes devem ser intrínsecas.

Este estudo objetivou identificar as práticas de governança corporativa na gestão estratégica de IFES do Nordeste, especificamente na concepção, execução e monitoramento da gestão estratégica. É importante destacar o crescimento de IFES no Nordeste, observadas ao longo dos últimos anos, e como elas vêm crescendo na forma de democratização do ensino superior e ampliando a democratização da participação cidadã no estabelecimento de seus objetivos estratégicos.

Não obstante às práticas de gestão participativa, as IFES apresentaram fragilidades no monitoramento de suas metas estratégicas, o que põe em risco o processo oneroso e demorado de criação dos objetivos estratégicos. Observa-se a necessidade premente de capacitação de pessoas, voltada para a formação de gestores. Somente com lideranças estratégicas e pessoas com visão holística é que os objetivos estratégicos poderão ser devidamente acompanhados e os planos de melhoria poderão ser realizados de forma eficaz e eficiente.

Propostasde investimento em ferramentas tecnológicas de gestão são outra questão a ser discutida nas IFES. Devido ao tamanho e complexidade dessas instituições e pelos inúmeros atores envolvidos, a tecnologia mostra-se essencial para manter as instituições ágeis para responder às demandas da comunidade e dos órgãos de controle externo, especialmente o Tribunal de Contas da União, que tem fornecido orientações para o aperfeiçoamento da gestão institucional.

Instituições públicas com fortes princípios de governança corporativa se mostrarão mais fortes para atravessar os períodos sombrios que o setor público atravessa em períodos cada vez mais constantes. Somente aquelas que justificarem sua presença na comunidade e que fizerem bom aproveitamento dos recursos é que poderão fornecer bons serviços e comprovar sua essencialidade aos stakeholders.

Dadas as limitações de abrangência geográfica, número de instituições que retornaram respostas e ao baixo envolvimento dado pelos respondentes às questões levantadas e encaminhadas pelo sistema, propõe-se a continuidade dos estudos com busca de maior envolvimento dos respondentes, maior profundidade na abordagem do tema e aumento no número de instituições pesquisadas. 


\section{REFERÊNCIAS}

AMARAL NETO, Francisco dos Santos. A EQUIDADE NO CÓDIGO CIVIL BRASILEIRO. Revista CEJ. Brasília-DF, v. 1, n. 25, p.16-23, jun. 2004. Disponível em: <https://goo.gl/spSMcG>. Acesso em: 10 out. 2016.

ANDRADE, Adriana; ROSSETTI, José Paschoal. Governança Corporativa: Fundamentos, Desenvolvimentos e Tendências, 4. ed. São Paulo: Atlas S.A, 2009, 584 p.

ANDRIOLA, Wagner Bandeira. PLANEJAMENTO ESTRATÉGICO E GESTÃO UNIVERSITÁRIA COMO ATIVIDADES ORIUNDAS DA AUTO-AVALIAÇÃO DE INSTIT: O EXEMPLO DA UNIVERSIDADE FEDERAL DO CEARÁ (UFC). Revista Iberoamericana de Evaluación Educativa. Madrid-España, v. 2, n. 2, p.82-103, 17 out. 2009. Anual. ISSN: 1989-0397. Disponível em: <https://goo.gl/TxBaaV>. Acesso em: 21 mai. 2016.

BIZERRA, Andre Luiz Villagelim; ALVES, Francisco José dos Santos; RIBEIRO, Cíntia de Melo de Albuquerque. Governança pública: uma proposta de conteúdo mínimo para os relatórios de gestão das entidades governamentais. In: ENCONTRO DA DIVISÃO DE ADMINISTRAÇÃO PÚBLICA/APB DA ANPAD - ENAPG, 5, 2012, Salvador-BA.Anais....Salvador: ANPAD, 2012, p. 1-16. Disponível em: <https://goo.gl/mIfclF>. Acesso em: 13 out. 2016.

BRASIL. Constituição (1988). Constituição da República Federativa do Brasil. Brasília- DF: Senado, 1988.

. Decreto n⿳o. 7.724, de 16 de maio de 2012. Regulamenta a Lei no ${ }^{\circ}$. 12.527, de 18 de novembro de 2011, que dispõe sobre o acesso a informações previsto no inciso XXXIII do caput do art. $5^{\circ}$., no inciso II do $\S 3^{\circ}$. do art. 37 e no $\S 2^{\circ}$. do art. 216 da Constituição.DECRETO: №. 7.724 DE 16 DE MAIO DE 2012. Brasília- DF: Diário Oficial da União, 16 maio 2012. Seção 1. Retificado em 18/05/2012.

. MINISTÉRIO DA TRANSPARÊNCIA FISCALIZAÇÃO E CONTROLADORIA GERAL DA UNIÃO CGU. E-SIC:Programa Brasil Transparente, 2016a. Disponível em: <https://goo. gl/jaGTL4>. Acesso em: 19 out. 2016.

. Secretaria de Planejamento Governança e Gestão. Tribunal de Contas da União Tcu.10 Passos para a boa Governança.Brasília-DF: TCU, 2014, 28 p. Disponível em: <https:// goo.gl/VWGV6K>. Acesso em: 12 out. 2016.

. Tribunal de Contas da União - TCU. (Org.).REFERENCIAL BÁSICO de GOVERNANÇA:Aplicável a Órgãos e Entidades da Administração Pública. Brasília: TCU, 2013, 57 p. Versão 1. Disponível em: <https://goo.gl/xXkP1u>. Acesso em: 13 out. 2016.

. Tribunal de Contas da União - TCU. (Org.).REFERENCIAL BÁSICO de GOVERNANÇA:Aplicável a Órgãos e Entidades da Administração Pública. Brasília: TCU, 2014, 57, p. Versão 2. Disponível em: <https://goo.gl/w9zeSg >. Acesso em: 25set. 2016.

. TRIBUNAL DE CONTAS DA UNIÃO - TCU. (Org.).Referencial para Avaliação da Governança do Centro de Governo.Brasília: TCU, 2016b, 99 p.

CARVAlHO, Cristina Amélia; VIEIRA, Marcelo Milano Falcão (Org.). ORGANIZAÇÕES,CULTURA E DESENVOLVIMENTO LOCAL:a agenda de pesquisa do observatório da realidade organizacional. Recife-PE: Edufepe, 2003, 366 p.

EVOLUÇÃO, 2015. 20 slides, color. Disponível em: <https://goo.gl/OGSwvB>. Acesso em: 13 out. 2016.

FLICK, Uwe. Introdução à pesquisa qualitativa,3. ed.Flick, Uwe. Porto Alegre: Artmed, 2009.

GIL, Antônio Carlos.Métodos e técnicas de pesquisa social,6. ed. São Paulo: Atlas S.A, 2008,200 p. 
IBGC, Instituto Brasileiro de Governança Corporativa - (Org.).Código das Melhores Práticas de Governança Corporativa,5. ed. São Paulo: IBGC, 2015, 108 p. Disponível em: <https://goo. gl/CI2CEQ>. Acesso em: 28 nov. 2016.

IFAC, International Federation of Accountants. Governance in the Public Sector: A Governing Body Perspective - Study 13. New York: International Federation of Accountants, 2001, 93 p. Disponívelem: <https://goo.gl/QAiHRy>. Acesso em: 25 set. 2016.

MAINARDES, Emerson Wagner; MIRANDA, Cristina Schmitt; CORREIA, Carlos Henrique. A gestão estratégica de instituições de ensino superior: um estudo multicaso. Contextus-Revista Contemporânea de Economia e Gestão, v. 9, n. 1, p. 19-32, 2011. Disponível em: <http://goo. gl/vI4PWS>. Acesso em: 4 set. 2016.

MATIAS-PEREIRA, José. A GOVERNANÇA CORPORATIVA APLICADA NO SETOR PÚBLICO BRASILEIRO.APGS- Administração Pública e Gestão Social. Viçosa, v. 2, n. 1, p.109-134, mar. 2010.

NARDES, Augusto. O controle externo como indutor da governança em prol do desenvolvimento. Revista do TCU, n. 127, p. 16-19, 2013.

PESSOA, Maria Naiula Monteiro.GESTÃO DAS UNIVERSIDADES FEDERAIS BRASILEIRAS:UM MODELO FUNDAMENTADO NO BALANCED SCORECARD, 2000, 304s. Tese (Doutorado) - Curso de Programa de Pós-graduação em Engenharia de Produção, Universidade Federal de Santa Catarina. Florianópolis-SC, 2000.

PRODANOV, Cleber Cristiano; FREITAS, Ernani Cesar de.Metodologia do trabalho científico [recurso eletrônico]:Métodos e Técnicas da Pesquisa e do Trabalho Acadêmico, 2. ed. Novo Hamburgo-RS: Universidade Feevale, 2013, 276 p. ISBN 978-85-7717-158-3. Disponível em: $<$ https://goo.gl/TC3Wsx>. Acesso em: 15 out. 2016.

SALES, Elana Carla de Albuquerque Silva et al. Governança no Setor Público Segundo a IFAC: Estudo nas Universidades Federais Brasileiras. In: ESTUDO NAS UNIVERSIDADES FEDERAIS BRASILEIRAS, 22, 2015, Foz do Iguaçu-PR. Anais.... Foz do Iguaçu: CBC - Congresso Brasileiro de Custos, 2015, p. 01-15.

SILVA, Edson Cordeiro da.Governança Corporativa nas Empresas: Guia prático de orientação para acionistas e Conselho Administrativo; Novo modelo de Gestão para redução do custo de capital e geração de valor ao negócio. São Paulo-SP: Atlas S.A, 2006, 181 p.

STEINERG, Herbert et al.A dimensão humana da Governança Corporativa:Pessoas criam as melhores e as piores práticas, 4. ed. São Paulo-SP: Gente, 2003, 247 p.

VILELA, André Luiz Nascimento; VELOSO, Letícia Helena Medeiros. GOVERNANÇA CORPORATIVA NAS INSTITUIÇÕES DE ENSINO SUPERIOR. In: COLÓQUIO INTERNACIONAL DE GESTÃO UNIVERSITÁRIA - CIGU: A GESTÃO DO CONHECIMENTO E OS NOVOS MODELOS DE UNIVERSIDADE, 14, 2014, Florianópolis-SC. Anais.... Florianópolis: Cigu, 2014, p. 1-9.

Recebido em: 20-4-2017

Aprovado em: 30-08-2017

Avaliado pelo sistema double blind review.

Editor: Elmo Tambosi Filho

Disponível em http://mjs.metodista.br/index.php/roc 